\title{
Feasibility study on using thioether as an emergency backup lubrication system on a large helicopter main gearbox
}

\section{Fang Duan ${ }^{1}$, Shy Chuan Tee $^{2}$, Michael Corsar ${ }^{3}$, Alastair Healey ${ }^{4}$, Werner Kleine-Beek ${ }^{4}$ and David Mba ${ }^{1}$}

\begin{abstract}
The oil lubrication system is a critical part of the helicopter main gearbox (MGB) and this is evident in the many accidents and incidents over the last 30 years. On a category " $A$ " rotorcraft a regulatory requirement mandates the MGB to sustain operation for at least 30 minutes following the loss of the primary oil lubrication pressure. The aim of this study was to undertake a comparative investigation into the performance of mist lubrication, using commercially available thioether (MCS-293 ${ }^{\mathrm{TM}}$ ), on a category "A" helicopter MGB under loss of oil conditions. Experimental observations highlighted that the high-speed input module of the MGB attained the highest temperature and was a limiting factor to continued gearbox operation under loss of oil conditions. Results showed that by routing thioether mist through existing galleries within the MGB a lower rate of temperature rise was achieved in comparison to a "dry" run condition.
\end{abstract}

\section{Keywords}

Helicopter main gearbox, emergency mist lubrication, thioether lubrication, dry lubrication, oil loss

\section{Introduction}

The helicopter main gearbox (MGB) is one of the critical components at power transmission as it converts the high rotation speed of gas turbines into the low speed while increasing torque to drive main and tail rotor systems. During flight, a significant amount of frictional heat is generated in the MGB and an oil lubrication scheme is essential to minimise physical wear and defects. Failure of lubrication system results from several events, such as lubrication pump failure, leaking lubricant, or ballistic damage. Numerous accidents and incidents related to faults of helicopter MGB lubrication system have been reported over the last 30 years ${ }^{1 ; 2}$. A category " $A$ " helicopter is defined as a multi-engined helicopter designed with engine and system isolation features. Typically such categories have a payload of 12-20 persons $^{3}$. As a regulatory requirement, the MGB of a category "A" rotorcraft has to sustain operation for at least 30 minutes to allow the rotorcraft to land safely after the loss of the primary oil lubrication pressure ${ }^{4 ; 5}$. Hence, an emergency backup lubrication system has been investigated by several groups to extend operation time period in the event of a loss of lubricant ${ }^{1 ; 4}$.

The development of an emergency oil lubrication system must consider weight, space, complexity and cost. In this context, the vapour-mist phase reaction lubrication (VMPL) system is a more suitable candidate compared to liquid lubrication system and other regular oil-mist and vapour lubrication systems. The liquid lubrication system has major disadvantage of weight, which for example can be as much as $15 \%$ of the total gas turbine engine weight ${ }^{6}$. In a conventional oil-mist lubrication system, there is no intended reaction between the mineral or synthetic hydrocarbon oil mist and the metal surfaces. The oil functions as a normal liquid lubricant within its operating temperature range. In gaseous lubrication system, the lubrication is achieved by a lubricious graphitic material generated by a light hydrocarbon gas, e.g. acetylene, when it decomposes on sufficiently high temperature surfaces. The VMPL differs from regular oil-mist and gaseous lubrication in terms of delivery, thermal decomposition and chemical reaction properties. In the VMPL technique, an organic liquid is delivered in the form of vapour or mist to high temperature mechanical components where the organic molecules react in the wearing surfaces. As a result, a lubricious deposit is generated to provide effective lubrication ${ }^{7}$. For example, the chemical reaction between a phosphate ester and iron containing surfaces produces a lubricious iron-phosphate type film or deposit, which can lubricate iron-based surfaces at temperatures greater than $300{ }^{\circ} \mathrm{C}$. However, a constant rapid reaction between the phosphate ester and the iron bearings and gears results in excessive wear ${ }^{8}$. In order to minimize this wear, a non-phosphorus reactive organic liquid, polyphenyl thioether, has been used to mist phase

\footnotetext{
${ }^{1}$ School of Engineering, London South Bank University, UK

${ }^{2}$ Air Logistics Department, Republic of Singapore Air Force (RSAF), Singapore

${ }^{3}$ School of Engineering, Cranfield University, UK

${ }^{4}$ European Aviation Safety Agency (EASA), Cologne, Germany
}

\section{Corresponding author:}

Fang Duan

School of Engineering, London South Bank University,

103 Borough Road, London, SE1 OAA, UK.

Email: duanf@Isbu.ac.uk 


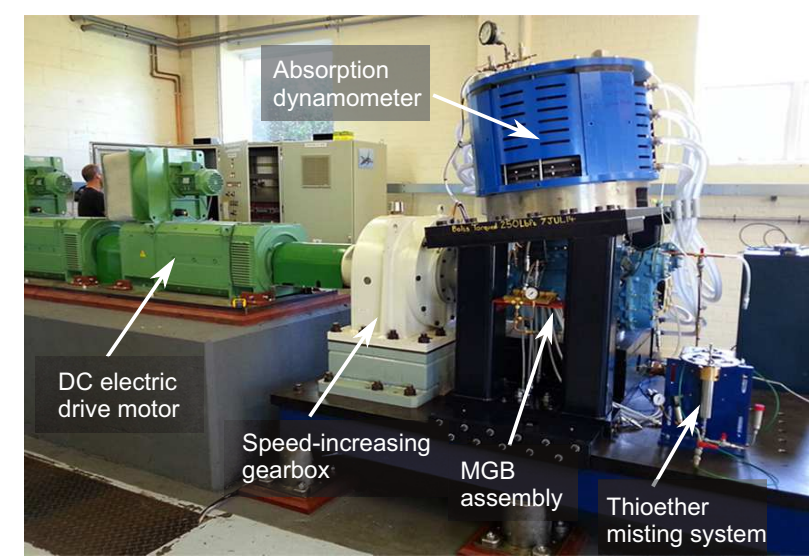

Figure 1. The MGB experimental rig for lubrication tests.

lubricate a spur gearbox rig operating at 10,000 rpm under highly loaded conditions ${ }^{4 ; 9}$. It has been shown that thioether in mist form generates a polymeric film that provides lubrication on the metal surfaces with minimal wear after 35 hours of operation with a constant operating temperature of $107{ }^{\circ} \mathrm{C}$. The simple single-stage gearbox experiment proved the effectiveness of thioether mist as an emergency lubricant.

This study extends the simple spur gearbox to a real size category " $\mathrm{A}$ " helicopter MGB experimental rig, including a drive system, MGB, absorption dynamometer and thioether misting system. The selected thioether (MCS-293 ${ }^{\mathrm{TM}}$ ) is misted and channelled into the MGB via 11 access ports. A total of 28 thermocouples were distributed in various locations of MGB to evaluate the performance of the thioether mist lubrication. In addition to temperature measurements, the oil pressure, flow rates and vibration levels were also monitored to ensure a safe operation of the test rig systems. The experiments were conducted in three stages and results from the tests revealed the effectiveness of thioether mist as an emergency lubricant. The study also explored the feasibility of delivering thioether mist lubrication into the internal gears and bearings of the MGB.

\section{Experimental rig}

The selected MGB has was a commercial category "A" MGB with two input models. During emergency lubrication conditions, it is recommended in the manufacture's operating manual that the torque on the MGB is reduced to $150 \mathrm{Nm}$ at an assumed speed of 22,000 rpm. The experimental rig for MGB lubrication test is shown in Fig. 1. A $750 \mathrm{~kW}$ DC electric drive motor, together with a speed increasing gearbox, provides a maximum input drive speed of $17,842 \mathrm{rpm}$ to the left hand forward reduction gear modules. An absorption dynamo-meter apply a resistance proportional to the desired loading on the MGB. The dynamometer was set to deliver a level of resistance that is equivalent to $293 \mathrm{~kW}$ loading at the MGB during the loss of the primary oil lubrication system. This power and torque load is proportional to that required under emergency lubrication conditions $(22,000 \mathrm{rpm}$ at $150 \mathrm{Nm})$. The equivalent frictional heat generated by internal gears and bearings was estimated to be approximately $20 \mathrm{~kW}$ at this load.

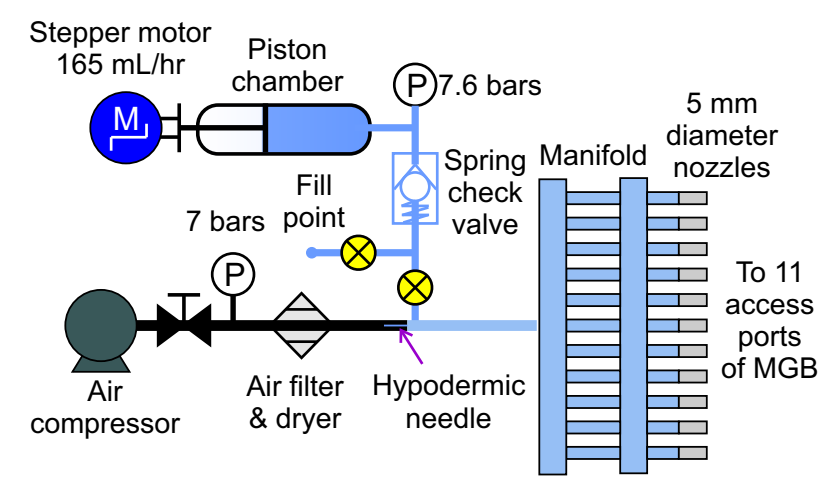

Figure 2. Thioether misting system.

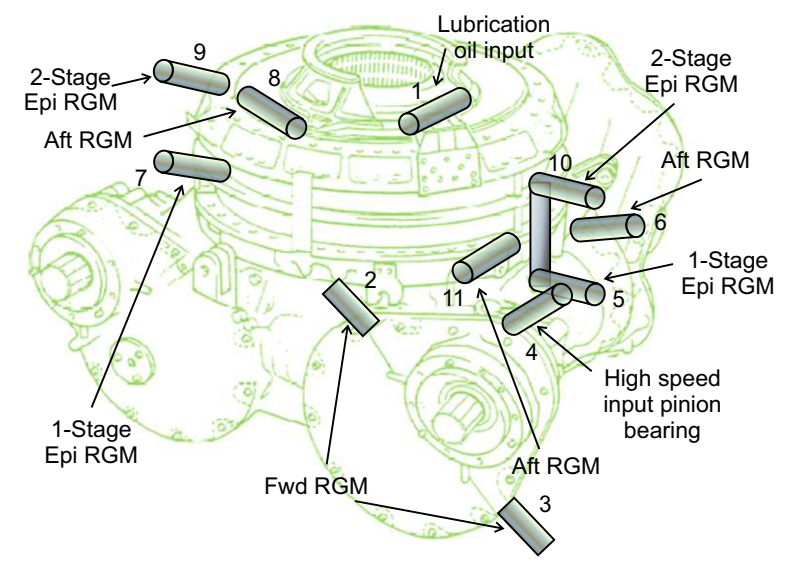

Figure 3. Access port for thioether mist delivery.
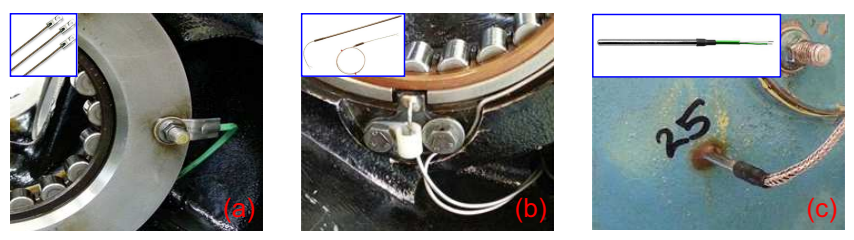

Figure 4. Three types of "K" thermocouples and installation on MGB, (a) washer, (b) sheath and (c) probe.

The thioether misting system is sketched in Fig. 2. Thioether liquid was held in a piston chamber driven by a stepper motor. It was pressurised to 7.6 bars before it was introduced into an airstream of 7 bars via a hypodermic needle. This mixture of thioether and air was then delivered through 11 misting nozzles (diameter of $5 \mathrm{~mm}$ ) to generate a fine thioether mist. The flowrate of $15 \mathrm{~mL} /$ hour per nozzle was the same as the experiments by Morales and Handschuh $^{9}$. The thioether mist lubricant was channelled through 11 access ports. The locations of these ports are shown in Fig. 3. The figure also indicates the five reduction gear modules of a commercial category " $\mathrm{A}$ " helicopter MGB: left hand (LH) and right hand (RH) forward (Fwd) reduction gear modules (RGMs), after (Aft) RGM, Main RGM and 2Stage epicyclic (Epi) RGM.

The temperature profile of the internal gears and bearings within the MGB was utilized to evaluate the the performance of VMPL lubrication. The type "K" thermocouple with nickel-chromium alloy and nickelaluminium alloy respectively as positive and negative electrodes was selected due to its fast response time and wide range of operating temperatures. Based on accessibility 


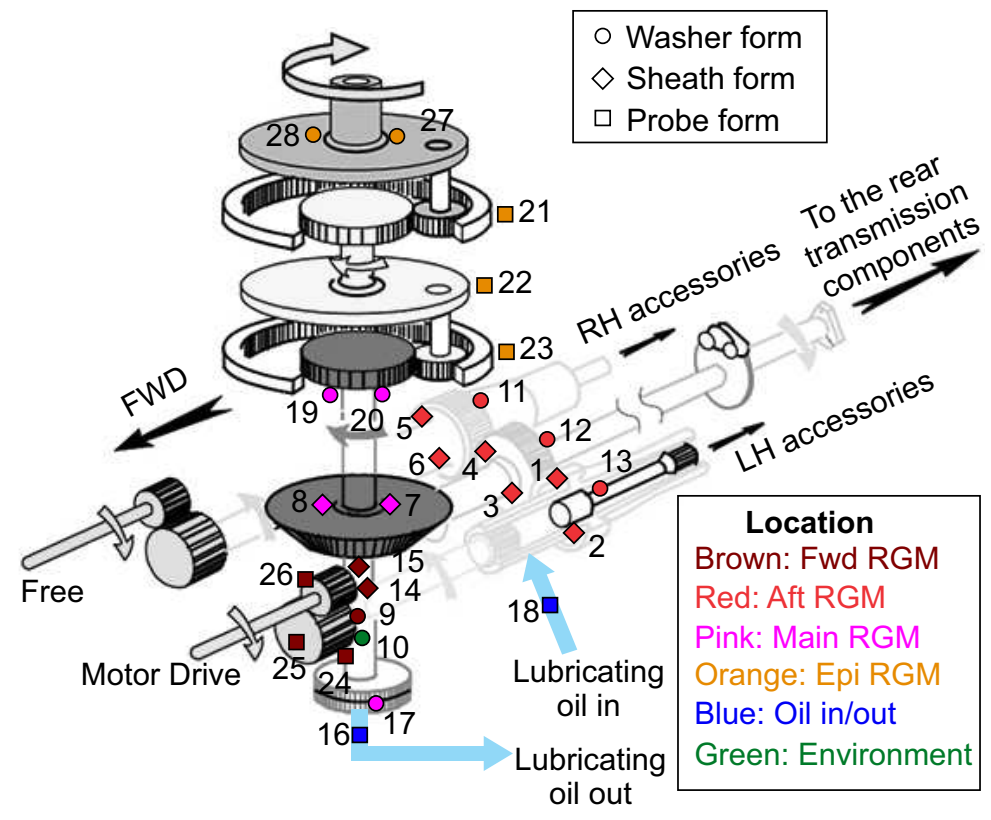

Figure 5. Thermocouple locations on MGB assembly.

Table 2. Thermocouples with highest temperature of each module

\begin{tabular}{|l|l|}
\hline \multicolumn{1}{|c|}{ Thermocouples } & \multicolumn{1}{c|}{ Module } \\
\hline Average value of thermocouple 14 and 15 & Fwd RGM \\
\hline Average value of thermocouple 1 and 2 & Aft RGM \\
\hline Average value of thermocouple 7 and 8 & Main RGM \\
\hline Thermocouple 23 & Epi RGM \\
\hline
\end{tabular}

and location of the bearing to be monitored, three types of " $\mathrm{K}$ " thermocouples, washer, sheath and probe, were selected, as shown in Fig. 4. The are respectively presented as circle, diamond and square in Fig. 5. The drive motor was only coupled to LH Fwd RGM. The RH Fwd RGM was free and hence no thermocouple was attached on RH Fwd RGM. The temperature profiles of four RGMs are presented henceforth. The colours of brown, red, pink and orange stand for the thermocouples located in LH Fwd RGM, Aft RGM, Main RGM and Epi RGM, respectively. The colours of blue and green respectively present the thermocouples for measuring lubricating oil in/out and environment temperature. The detailed locations of all 28 thermocouples are summarized in table 1. Two thermocouples were placed at every bearing position in the experiment. The thermocouples were connected to a National Instruments (NI) Data Acquisition (DAQ) device (P/N: NI cDAQ-9174) with sampling frequency of $5 \mathrm{~Hz}$. In addition to temperature, the oil pressure, flow rates and vibration levels were also monitored to ensure the safe and proper operation of the lubrication experiments.

\section{Results and Discussion}

The experiments were conducted in three progressive stages to ensure a safe operation of the test rig systems while preserving the integrity of the MGB. Thermocouples with highest temperature of each module were selected to present the temperature profile of the respective MGB module, as shown in table 2.
Table 1. Location of 28 thermocouples

\begin{tabular}{|c|c|c|}
\hline \multicolumn{2}{|c|}{ No. } & Location \\
\hline $1 / 2$ & $\diamond$ & Fwd Brg LH Aft RGM \\
\hline $3 / 4$ & $\nabla$ & Fwd Brg Cen Aft RGM \\
\hline $5 / 6$ & $\nabla$ & Fwd Brg RH Aft RGM \\
\hline $7 / 8$ & $\nabla$ & Brg Bevel \\
\hline 9 & O & Aft Brg LH Fwd RGM \\
\hline 10 & 0 & Ambient Temperature \\
\hline 11 & O & Aft Brg RH Aft RGM \\
\hline 12 & 0 & Aft Brg Cen Aft RGM \\
\hline 13 & 0 & Aft Brg LH Aft RGM \\
\hline $14 / 15$ & $\nabla$ & Aft Brg LH Fwd RGM \\
\hline 16 & $\overline{\mathbf{D}}$ & Lubricating oil out \\
\hline 17 & 0 & Sump Plate \\
\hline 18 & $\bar{\square}$ & Lubricating oil in \\
\hline $19 / 20$ & 0 & Brg Bevel Plate \\
\hline 21 & $\square$ & 2nd Epi Case \\
\hline 22 & $\square$ & Epi Case Ring \\
\hline 23 & $\square$ & $1^{\text {st }}$ Epi Case \\
\hline 24 & $\mathbf{\square}$ & Aft Brg LH Fwd RGM \\
\hline 25 & $\mathbf{\square}$ & Fwg Brg LH Fwd RGM \\
\hline 26 & 口 & Fwd Brg LH Input \\
\hline $27 / 28$ & 0 & Output Brg \\
\hline \multicolumn{2}{|l|}{ Aft: Aft } & Fwd: Forward \\
\hline \multicolumn{2}{|c|}{ Brg: Bearing } & LH: Left hand \\
\hline \multirow{2}{*}{\multicolumn{2}{|c|}{ Cen: Center }} & RGM: Reduction gear module \\
\hline & & RH: Right hand \\
\hline
\end{tabular}

\section{Partial Commissioning Test without Loading}

The first stage of experiments involved operating the test rig under no-load conditions to ensure the safe and proper 

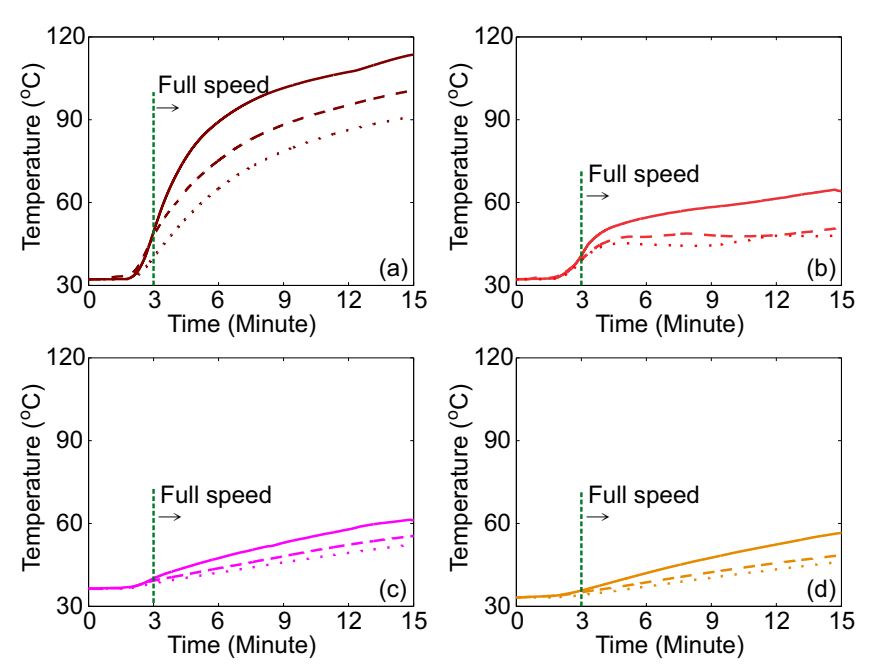

- Normal lubrication $\quad$... . Thioether mist lubrication
- - - "Oil off"

Figure 6. Temperature profile of modules under different lubricating conditions without loading. (a) Fwd RGM; (b) Aft RGM; (c) Main RGM; (d) Epi RGM.

operation of the driving DC electric motor, the speedincreasing gearbox, the lubrication and cooling systems, the thioether misting system and the data acquisition system. The temperature profiles of the MGB gears and bearings were recorded under the three lubrication conditions: normal lubrication, "oil-off" condition and thioether mist lubrication, all under no-load conditions. For the purpose of safety and preserving the integrity of the MGB, the test duration was set to 30 minutes and a test abort temperature limit was $150{ }^{\circ} \mathrm{C}$.

Fig. 6 shows the temperature profile under no-load conditions for the four RGMs. The temperature of these modules increased after the input speed of MGB reached $17,842 \mathrm{rpm}$ at 3 minutes of operation. Under these three lubricating conditions, the highest temperature was observed at thermocouples of 14 and 15 located at Aft Brg LH Fwd RGM, as shown in Fig. 6(a). Unexpectedly, the temperature of "oil-off" was lower than that of normal lubrication condition at all four modules. This observation can be explained as follows: In a typical gearbox, $50 \%$ of the total power losses can be attributed to bearings, $40 \%$ to gear meshing and the remaining $10 \%$ to windage and churning losses ${ }^{10}$. These power losses result in heat generation. Windage power loss is defined as the power loss due to the fluid drag when the gear is running in air. Churning power loss is the power loss due to the acceleration of the oil by the gear teeth and the pumping of the oil trapped between the gear meshing (also known as air-oil pocketing loss). Hachiro et. al. noted that windage losses increase with speed while churning losses increase with both speed and lubrication oil pressure ${ }^{11}$. For this investigation, the windage losses of all three tests is comparable because the input speed is constant. The churning loss of the MGB under normal lubrication will be higher than that of the "oil-off" condition and thioether mist lubrication. As a result of the combined losses under these operating conditions, more frictional heat would be generated under the normal lubrication condition than the "oil-off" condition within the MGB. Therefore, the
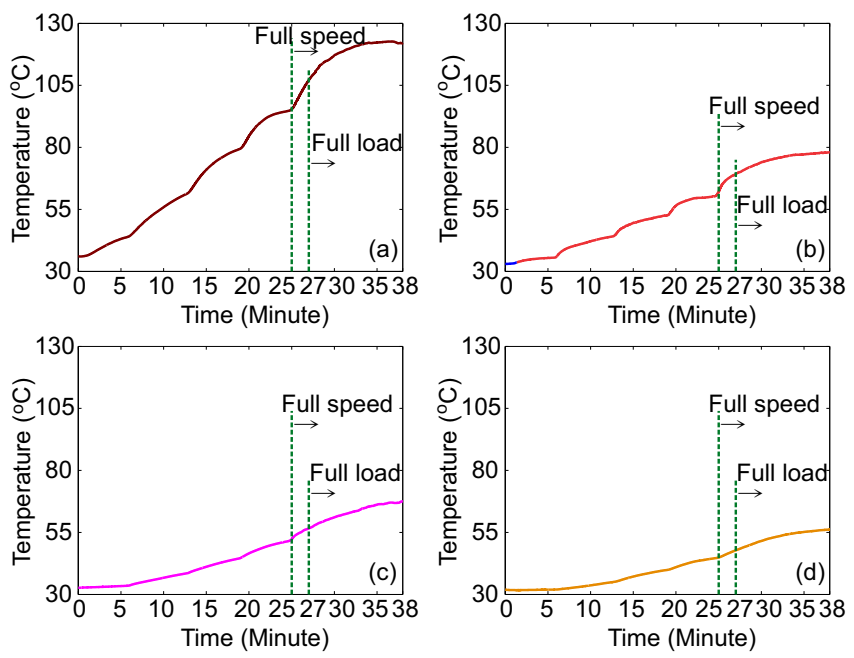

Figure 7. Temperature profile of modules under normal lubricating conditions with progressive loading. (a) Fwd RGM; (b) Aft RGM; (c) Main RGM; (d) Epi RGM.

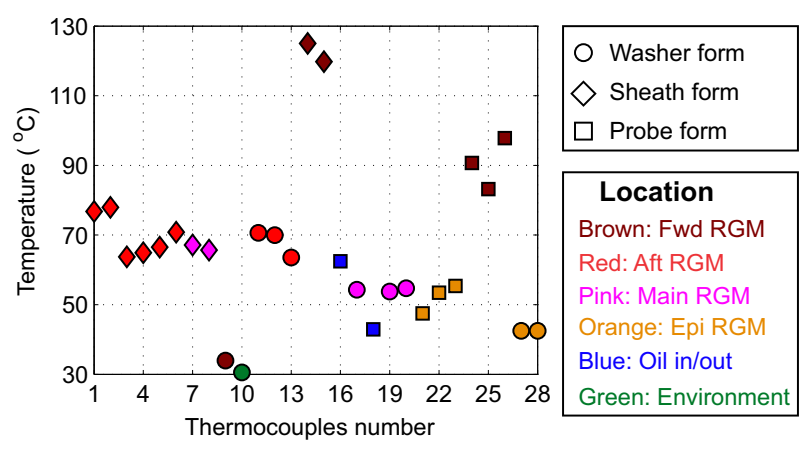

Figure 8. Temperature of all thermocouples under normal lubricating conditions and full loading at thermal equilibrium.

temperature under the "oil-off" condition will be lower than under normal lubrication.

\section{Partial Commissioning Test with Loading}

The second stage of testing involved operating the testrig under normal lubricating conditions at full test load $(293 \mathrm{~kW})$. The input speed and load on the MGB were progressive increased, as shown in Fig. 7. For example, the input drive speed was progressively increased to full speed of 17,842 rpm at 25 minutes of operation. From 25 to 27 minutes, the load was increased from $200 \mathrm{~kW}$ to full load of $293 \mathrm{~kW}$. The test at full load and speed lasted until thermal equilibrium of the MGB was established at 36 minutes of operation. Thermal equilibrium was defined as the condition in which the rate of change of bearing and gear temperature was less than 2 degrees centigrade per 5 minutes of operation $\left(<2{ }^{\circ} \mathrm{C} / 5\right.$ minutes). Data from this test phase formed the baseline thermal map for normal lubrication conditions and was the reference point for lubrication tests in stage three.

Fig. 8 indicates that the different MGB modules attained different temperatures when operating at thermal equilibrium. The temperature was the highest at the Fwd RGM. This suggests that the dominant frictional losses for the MGB, as manifested by the temperature of the modules, are more influenced by the shaft's rotational speed than its transmission torque. This inference was based on the 
Table 3. The operating procedure and temperature of MGB for the "oil-off" test.

\begin{tabular}{|l|l|l|l|l|l|}
\hline \multirow{2}{*}{ Time } & \multirow{2}{*}{ Description } & \multicolumn{3}{|l|}{ Temperature at end of phase } \\
\cline { 3 - 6 } & & Fwd & Aft & Main & Epi \\
\hline $0-5$ & Progressively increase to full speed & 52.34 & 34.06 & 32.32 & 27.92 \\
\hline $5-21$ & Introduce full load under normal lubrication & 120.52 & 74.92 & 62.26 & 51.80 \\
\hline \multirow{2}{*}{$21-23$} & $\begin{array}{l}\text { Remove load } \\
\text { Stop lubricant pump } \\
\text { Suck lubricant from MGB } \\
\text { Lower speed to 5947 rpm } \\
\text { Blow out lubricant using compressed air }\end{array}$ & 126.90 & 69.85 & 62.81 & 52.95 \\
\hline $23-27$ & Increase to full speed & 134.1 & 85.46 & 68.37 & 62.31 \\
\hline $27-34$ & Introduce full load & 183.05 & 104.43 & 83.22 & 88.52 \\
\hline $34-36$ & Remove load and stop drive motor & 195.80 & 98.18 & 84.81 & 89.46 \\
\hline
\end{tabular}

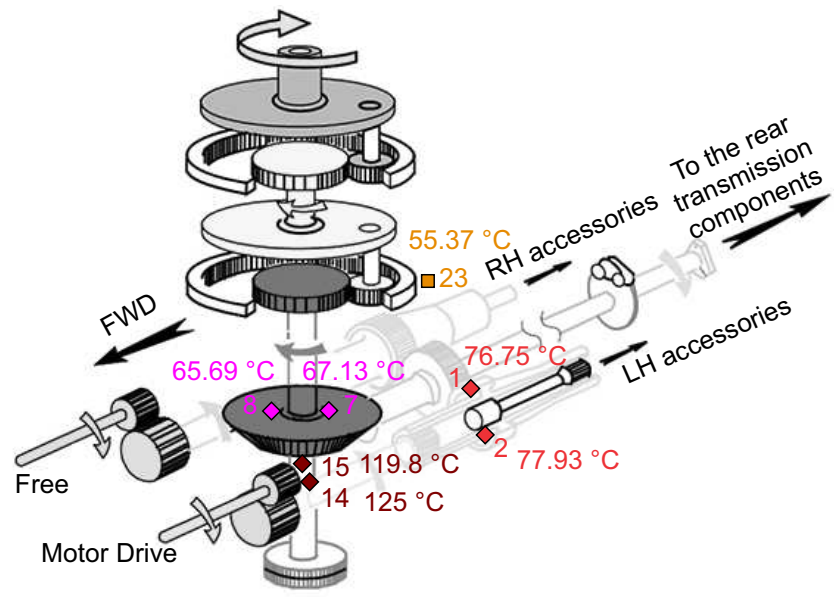

Figure 9. Thermocouples with highest temperature of each module.

direct temperature measurements of the bearing assemblies located in the Fwd, Aft and Main RGMs. Thermocouples with highest temperature of each module are shown in Fig 9. For the Epi RGM, the temperature reading taken at the $1^{\text {st }}$ stage case gear provides an indirect measurement of the $1^{\text {st }}$ stage planetary gear bearing assembly. Although the $1^{\text {st }}$ stage planetary gear shaft rotates at a higher speed than the bevel wheel, the lower temperature reading is attributed to the thermal gradient resulting from the heat conduction process between the bearing assemblies to the case gear, noting that all other temperature measurements are taken directly from the various bearings.

\section{3. "Oil-off", Thioether Mist Lubrication and "Dry gear" Test Conditions with Loading}

Stage three of testing provided a comparison of the temperature profile and rate of temperature rise of each MGB module under different lubricating conditions upon attaining thermal equilibrium at full speed and load. The abort temperature limit for the Stage 3 tests was set as $200{ }^{\circ} \mathrm{C}$. Each test started under normal lubrication conditions which offered an opportunity to compare results with previous tests (stage2), see Fig. 8. Stage three consists of three test conditions, i.e. "oil-off", thioether mist lubrication and "dry gear" test conditions. The first two conditions required the MGB to operate at full speed and load under normal lubrication condition until thermal equilibrium had been

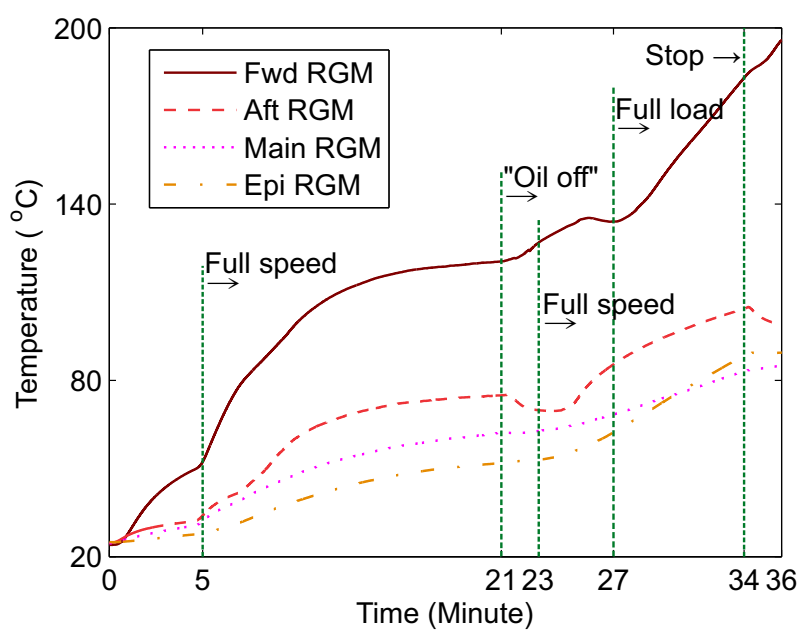

Figure 10. Temperature profile of MGB under "oil-off" condition.

reached before switching the lubrication condition to "oiloff" and thioether mist respectively.

Prior to subjecting the MGB to these conditions, and exactly at the moment the normal lubrication condition was stopped, short bursts of compressed air was delivered through the MGB inlet port to purge remnants of lubrication oil within the internal galleries. Purging with compressed air was required to ensure that the oil passages for delivery of the mist were free of residual oil that could have hindered mist delivery rates. This exercise of purging lasted for no more than 2-minutes and ensured restriction-free routing of the thioether mist during delivery while allowing a true comparison to be made between the "oil-off" and thioether mist lubricating conditions. The third test, "dry gear" condition, involved operating the MGB at full speed and load $(293 \mathrm{~kW})$ in the absence of residual oil. To remove all residual oil, the MGB was first operated at low speed and without load to fling off oil remnants on the gear teeth and the bearing surfaces. Again purging with compressed air was employed to ensure that the oil passages were removed of ruminant oil. This procedure also lasted approximately 2 minutes.

The operating procedure of the "oil-off" test is listed in table 3 and the temperature profiles of four RGMs is shown in Fig. 10. Full load was introduced after the input speed of MGB was progressively increased to full speed at 5 minutes. The recorded temperature of RGMs under normal lubrication at thermal equilibrium (21 minutes) was 
Table 4. The operating procedure and temperature of the thioether mist lubrication test.

\begin{tabular}{|l|l|l|l|l|l|}
\hline \multirow{2}{*}{ Time } & \multirow{2}{*}{ Description } & \multicolumn{4}{|l|}{ Temperature at end of phase } \\
\cline { 3 - 6 } & & Fwd & Aft & Main & Epi \\
\hline $0-2$ & Progressively increase to full speed & 68.81 & 54.73 & 53.63 & 49.92 \\
\hline $2-12$ & Introduce full load under normal lubrication & 114.86 & 76.40 & 62.80 & 53.69 \\
\hline $12-23$ & Drain lubricant & 133.78 & 89.06 & 74.06 & 70.00 \\
\hline $23-30$ & $\begin{array}{l}\text { Full speed and load under } \\
\text { thioether mist lubrication }\end{array}$ & 187.33 & 111.62 & 90.84 & 95.23 \\
\hline $30-36$ & Remove load and stop drive motor & 180.53 & 95.46 & 89.06 & 94.99 \\
\hline
\end{tabular}

Time in minutes; Temperature in ${ }^{\circ} \mathrm{C}$

Table 5. The operating procedure and temperature of the "dry gear" test.

\begin{tabular}{|l|l|l|l|l|l|}
\hline \multirow{2}{*}{ Time } & \multirow{2}{*}{ Description } & \multicolumn{4}{|l|}{ Temperature at end of phase } \\
\cline { 3 - 6 } & & Fwd & Aft & Main & Epi \\
\hline $0-9$ & Drain lubricant at low speed & 55.55 & 54.05 & 52.70 & 54.38 \\
\hline $9-22$ & Full speed under "dry gear" condition & 116.55 & 85.09 & 70.13 & 73.35 \\
\hline $22-28$ & Full speed \& load under "dry gear" condition & 172.78 & 129.34 & 94.59 & 99.87 \\
\hline $28-36$ & Remove load and stop drive motor & 172.04 & 106.06 & 95.18 & 94.99 \\
\hline
\end{tabular}

Time in minutes; Temperature in ${ }^{\circ} \mathrm{C}$

comparable with these values in the stage 2 test (Fig. 8). After validation, the "oil-off" test was conducted following the procedure in table 3 . The temperature of RGMs were rapidly increased when the full load was re-introduced again at 27 minutes. Temperature at the Aft bearing of the LH input pinion (thermocouples 14 and 15) was observed to rise slowly from an average reading of $183.05^{\circ} \mathrm{C}$ to $195.80^{\circ} \mathrm{C}$ at the point where the load was taken off from the MGB at 34 minutes. There was an increase in temperature across all RGMs from 27 minutes of operation, see Fig. 10. The rate of temperature rise is presented and compared to the thioether mist lubrication and "dry gear" tests in Fig. 13.

In the thioether mist lubrication test, the same operating procedure as the "oil-off" test was undertaken. The thioether mist MCS-293 ${ }^{\mathrm{TM}}$ was supplied to MGB at 23 minutes under the full speed and load condition after the lubricating oil was drained from MGB. The temperature of RGMs at the end of phase were tabulated in table 4 , while the temperature profiles is shown in Fig. 11. Comparing table 3 and Fig. 10 to table 4 and Fig. 11, the temperature profiles and temperatures at the end of phase were similar except the final stage after removing load. From Fig. 11, it was interesting to note that when the load was taken off the MGB under thioether mist lubrication, temperatures at the Aft bearing of the LH input pinion (thermocouples 14 and 15) tapered off before receding. This was aligned with the suggestion of the lubricating characteristic of the thioether mist lubricant in Section 3.1.

The third test condition, "dry gear" was introduced with the operating procedure detail in table 5. The temperature profiles of four RGMs is shown in Fig. 12. The MGB was operated under no load and full speed before subjected to full loading of $293 \mathrm{~kW}$. This allowed the gears and bearings to fling off any residual oil that may provide some form of boundary lubrication for the contacting metal surfaces.

The comparison of the MGB performance under the different lubricating conditions were based on the rates of temperature rise across the MGB during the short operating duration of 6 to 7 minutes, following a state of thermal equilibrium at full load. Results of this comparison are shown in Fig. 13. The rate of temperature rise of all the

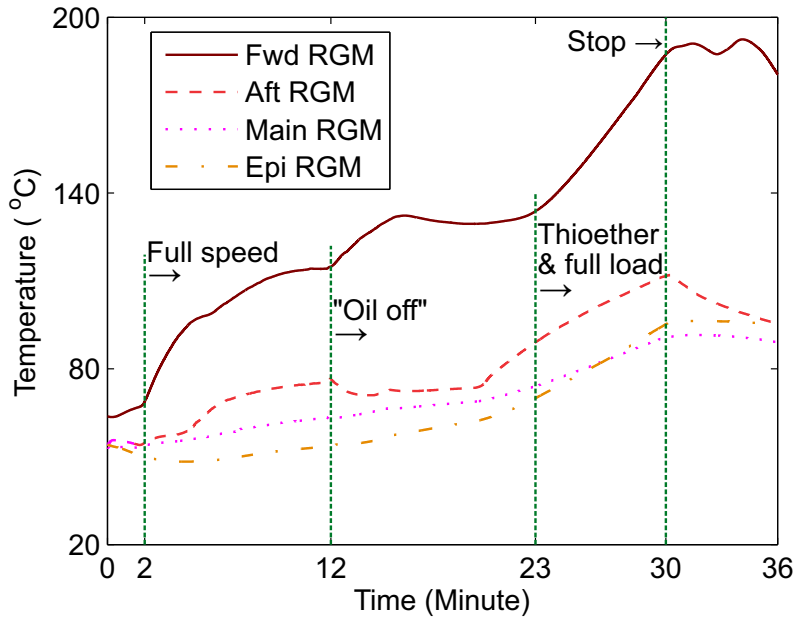

Figure 11. Temperature profile of MGB under thioether mist lubrication.

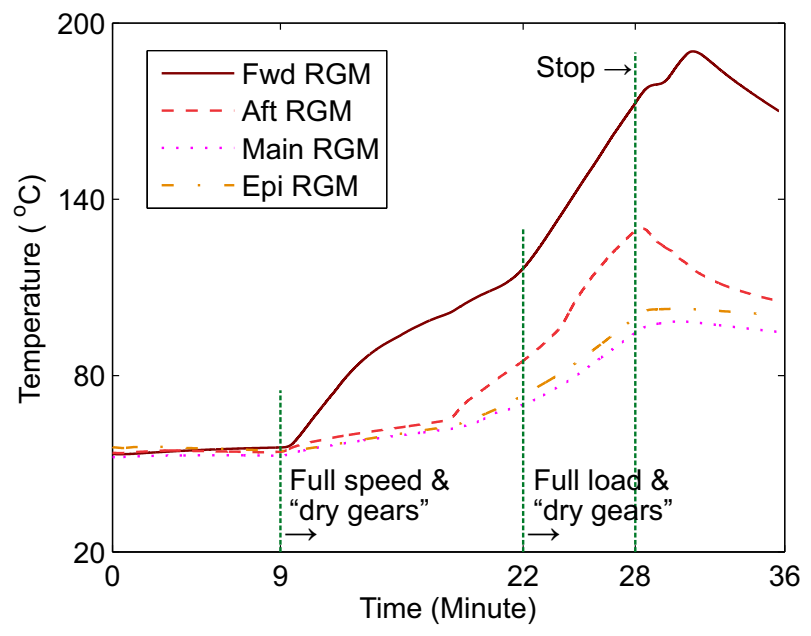

Figure 12. Temperature profile of MGB under "dry gear" condition.

MGB modules revealed the highest temperature rises were experienced by the gears and bearings operating under "dry" condition. Similar to the temperature readings obtained 


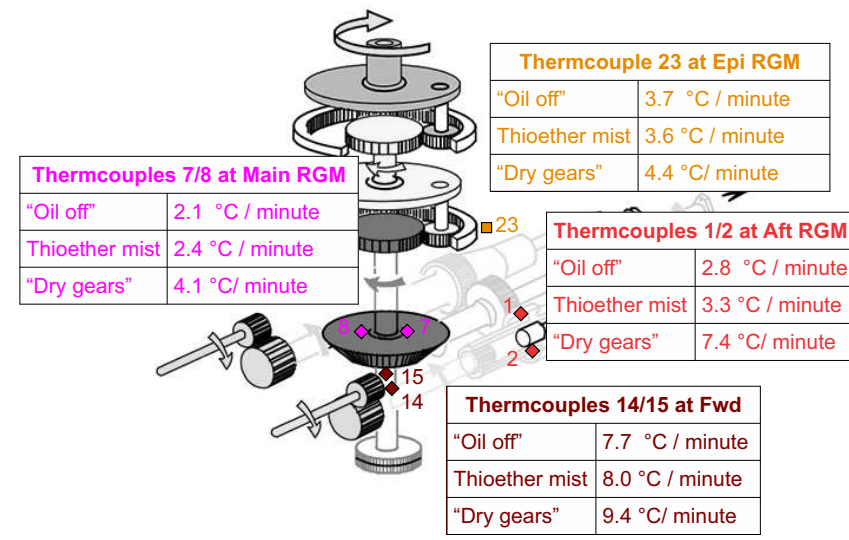

Figure 13. Overview of rate of temperature rise across the MGB modules under various lubricating conditions and full load $(293 \mathrm{~kW})$

during thermal equilibrium, the rate of the temperature rise was the highest at the Fwd RGM when compared to the rest of the modules.

The rate of temperature rise, for each of the MGB modules, under thioether mist lubrication was comparable to that of "oil-off" condition. However, it is important to note that the observations were made over a short operating duration of 6 to 7 minutes, following the MGB operation at thermal equilibrium. The duration was limited by the abort temperature limit that was reached by the Fwd RGM during the Stage 3 tests. As the MGB was operating under normal lubrication at thermal equilibrium, the short duration under the "oil-off" and thioether mist conditions might have been influenced by residual oil on the gears and bearings. This implied that the similar rate of temperature rise during both "oil-off" and thioether mist lubrication tests was attributed to the boundary lubricating conditions from the residual oil. It also suggests that if the MGB was operated in these two conditions for a prolonged duration, which is currently not possible given the thermal limitations of the Fwd RGM, one might observe a different rate of temperature rise for each of the test condition. This hypothesis was supported by the higher rate of temperature rise under the "dry gear" condition, which was akin to operating the MGB over a prolonged duration to eliminate any presence of residual lubrication oil in gear meshes and bearings.

\section{Conclusion}

An experimental rig was designed and built to investigate the feasibility of using the thioether (MCS-293 ${ }^{\mathrm{TM}}$ ) as an emergency mist lubricant in a helicopter MGB. The temperature profiles of several components within the MGB were monitored to evaluate the performance of the thioether mist lubricant. Comparative experimental conditions investigated included normal lubrication, thioether mist lubrication and dry operation. Observations showed the highest rate of increase in temperature, under all test conditions, was at the Fwd RGM. Results also showed that there was a lower rate of temperature rise within the gearbox for thioether mist lubrication as comparable to the dry operating condition. The experiment also validated the feasibility of delivering thioether mist lubrication into the internal gears and bearings of the MGB using the existing oil lubrication galleries as well as supplementary access ports located across the MGB assembly.

\section{Acknowledgements}

The research is conducted under the project contract European Aviation Safety Agency (EASA), $\mathrm{N}^{\circ}$ EASA.2012.C30, entitled "HELMGOP I- HELicopter Main Gearbox loss of Oil Performance optimisation".

\section{References}

1. D. Mba, S. Place, H. Rashid, R.L.C Keong, Helicopter main gearbox loss of oil performance optimization - HELMGOP, Tech. rep., European Aviation Safety Agency (EASA), $\mathrm{N}^{\circ}$ EASA.2012.C30, (2011).

2. National transportation safety board, [Online]. Available: http://www.ntsb.gov/_layouts/ntsb.aviation/Results.aspx?query $\mathrm{Id}=580 \mathrm{~d} 7 \mathrm{bff}-5188-423 \mathrm{c}-\mathrm{b} 7 \mathrm{ac}-\mathrm{cc} 4 \mathrm{e} 236 \mathrm{e} 6 \mathrm{ae} 8$

3. European Aviation Safety Agency (EASA), Annexes to the draft commission regulation on air operations - OPS, EASA, Germany.

4. R. F. Handschuh, W. Morales, Lubrication system failure baseline testing on an aerospace quality gear mesh, Tech. Rep. NASA/TM2000-209954, NASA (2000).

5. European Aviation Safety Agency (EASA), Large Helicopter Main Gearbox Certification Requirements, CS 29.927(c), EASA, Germany, (2013).

6. K. W. Van Treuren, D. N. Barlow, W. H. Heiser, M. J. Wagner, N. H. Forster, Investigation of vapor-phase lubrication in a gas turbine engine, Journal of engineering for gas turbines and power 120 (2) (1998) 257-262.

7. E. E. Klaus, J. Phillips, S. C. Lin, N. L. Wu, J. L. Duda, Structure of films formed during the deposition of lubrication molecules on iron and silicon carbide, Tribology Transactions 33 (1) (1990) 25-32.

8. A. Nagarajan, C. Garrido, J. Gatica, W. Morales, Phosphate reactions as mechanisms of high-temperature lubrication, Tech. Rep. NASA/TM2006-214060, NASA (2006).

9. W. Morales, R. F. Handschuh, T. L. Krantz, Feasibility study of vapor-mist phase reaction lubrication using a thioether liquid, Tribology Transactions 52 (3) (2009) 370-375.

10. A. A. Lord, An experimental investigation of geometric and oil flow effects on gear windage and meshing losses, Ph.D. thesis, University of Wales, Swansea, United England (1998).

11. M. Hachiro, I. Yuuichi, P. T. Dennis, Effects of lubrication on the performance of high speed spur gears, Tech. Rep. NASA TM-101969, NASA (1989). 